\title{
KEMAMPUAN PEGAWAI DAN IMPLIKASINYA TERHADAP KINERJA PEGAWAI PADA DINAS LINGKUNGAN HIDUP KOTA SUKABUMI
}

\author{
Andi Riyanto', Rusli Nugraha ${ }^{2}$, Satia Suhada ${ }^{3}$ \\ 1,2 Universitas Bina Sarana Informatika \\ e-mail: andi.iio@bsi.ac.id, rusli.rng@bsi.ac.id \\ ${ }^{3}$ STMIK Nusa Mandiri \\ e-mail: satia.sha@nusamandiri.ac.id
}

\begin{abstract}
Abtraksi
Sumber daya manusia merupakan faktor paling penting dalam melaksanakan tugas pokok dan fungsi pegawai Dinas Lingkungan Hidup Kota Sukabumi.Tolak ukur prestasi kerja pada Dinas Lingkungan Hidup Kota Sukabumi merupakan kemampuan pegawai untuk dapat meningkatkan kualitas pelayanan umum secara optimal. Keberhasilan atau kegagalan kinerja pegawai Dinas Lingkuhan Hidrup Kota Sukabumi dipengaruhi oleh tingkat kinerja pegawai secara individu atau dalam kelompok. Dengan asumsi semakin baik kinerja pegawai maka semakin baik kinerja entitas. Untuk itu entitas perlu menetapkan tujuan kinerja pegawai yang akan dicapai. Dari hasil penelitian diperoleh nilai koefisien determinasi sebesar $74,48 \%$ menunjukkan besarnya efek dari kemampuan pegawai terhadap kinerja pegawai, sisanya sebesar $25,52 \%$ dipengaruhi oleh variabel lain, maka DLH Kota Sukabumi perlu terus berupaya meningkatkan kemampuan pegawainya untuk meningkatkan kinerja, baik pegawai maupun organisasi, melalui pelatihanpelatihan ataupun dengan melakukan rotasi pegawai
\end{abstract}

Kata Kunci: Kemampuan pegawai, kinerja pegawai

\begin{abstract}
Abstact
Human resources are the most important factor in carrying out the main tasks and functions of the Department of Environment employees in Sukabumi City. The measure of work performance in the Department of Environment of Sukabumi City is the ability of employees to be able to improve the quality of public services optimally. The success or failure of the performance of employees of the Hidrup City Department of Sukabumi City is influenced by the level of performance of employees individually or in groups. Assuming the better the performance of employees, the better the performance of the entity. For this reason, entities need to set goals for employee performance to be achieved. From the results of the study, the determination coefficient value of $74.48 \%$ indicates the magnitude of the effect of the ability of employees on employee performance, the remaining $25.52 \%$ is influenced by other variables, the DLH of Sukabumi City needs to continue to improve the ability of employees to improve performance, both employees and organization, through training or by rotating employees.
\end{abstract}

Keywords: Employee ability, employee performance

\section{Pendahuluan}

Dinas Lingkungan Hidup Kota

Sukabumi (DLH) adalah Satuan Kerja

Perangkat Daerah (SKPD) yang mempunyai

tugas pokok melaksanakan urusan

Pemerintahan Daerah dan tugas pembantuan

yang diberikan di bidang lingkungan hidup

(Perwalkot, 2016). Seiring dengan meningkatnya populasi penduduk, perekonomian, dan pembangunan di wilayah Kota Sukabumi, peran DLH sangat krusial dibutuhkan, dimana fungsi DLH adalah merumuskan kebijakan operasional, pembinaan, pelaksanaan, pengawasan dan pengelolaan serta perlindungan lingkungan hidup dan juga memberikan pelayanan umum kepada masyarakat. Dengan pertumbuhan 
Kota Sukabumi di berbagai bidang tersebut maka dengan sendirinya akan menimbulkan berbagai masalah lingkungan sebagai ekses perkembangan kota yang cukup pesat. Berbagai dampak lingkungan yang ditimbulkan antara lain meningkatnya volume sampah yang dihasilkan dari sampah rumah tangga dan sampah pasar yang mana setiap hari produk sampah dari masyarakat rata-rata sekitar 165 ton (Antaranews.com, 2018), tidak terealisasinya Ruang Terbuka Hijau (RTH) secara integrasi yakni 30 persen luas kota (RTH) publiknya 20 persen, dan (RTH) privatnya 10 persen (Pojokjabar.com, 2017), RTH yang semakin berkurang dan kebutuhan lahan pemakaman yang semakin luas, sehingga aspek-aspek tersebut memerlukan penanganan yang serius dari DLH Kota Sukabumi.

Untuk meningkatkan kualitas pelayanan terhadap masyarakat Kota Sukabumi, maka seluruh pegawai DLH Kota Sukabumi dituntut untuk meningkatkan kemampuan yang dimilikinya agar tercapai kinerja yang lebih baik, sebab apabila pegawai DLH Kota Sukabumi memiliki kemampuan yang baik, maka dengan sendirinya pelayanan terhadap masyarakat Kota Sukabumi oleh DLH juga akan lebih baik.

Manusia sebagai unsur utama dalam tercapainya tujuan suatu entitas, sudah barang tentu dituntut memiliki kemampuan, keterampilan, ketekunan dan motivasi yang baik yang dibutuhkan dalam menyelesaikan tugas yang diberikan kepadanya. Untuk mencapai hasil yang optimal dalam memberikan pelayanan kepada masyarakat, sudah seharusnya semua entitas pemerintahan harus menempatkan pegawai sesuai dengan kemampuannya agar tercapainya pelayanan yang maksimal kepada masyarakat.

Masalah yang dihadapi oleh DLH Kota Sukabumi dalam upaya meningkatkan kinerja pegawainya diantaranya adalah menempatkan pegawai yang tidak sesuai dengan kemampuan atau latar belakang pendidikan. Kondisi ini menyebabkan kinerja pegawai DLH yang tidak optimal bahkan dapat dikatakan cederung agak menurun, hal ini dapat dilihat dari berbagai aspek menurunnya hasil kinerja pegawai pada DLH yang tertera pada tabel berikut:

\section{Tabel 1. Penempatan Pegawai pada DLH Kota Sukabumi}

\begin{tabular}{|l|c|c|c|c|c|}
\hline \multirow{2}{*}{ Uraian } & \multicolumn{2}{|c|}{ Tahun 2016 } & \multicolumn{2}{c|}{ Tahun 2017 } & \multirow{2}{*}{$\begin{array}{c}\text { Keteranga } \\
\mathrm{n}\end{array}$} \\
\cline { 2 - 5 } & $\begin{array}{c}\text { Targ } \\
\text { et }\end{array}$ & $\begin{array}{c}\text { Reali } \\
\text { sasi }\end{array}$ & $\begin{array}{c}\text { Targ } \\
\text { et }\end{array}$ & $\begin{array}{c}\text { Reali } \\
\text { sasi }\end{array}$ & \\
\hline $\begin{array}{l}\text { Kinerja } \\
\text { Pengelola } \\
\text { an } \\
\begin{array}{l}\text { Lingkunga } \\
\text { n Hidup }\end{array}\end{array}$ & $80 \%$ & $75 \%$ & $80 \%$ & $70 \%$ & $\begin{array}{l}\text { Penempata } \\
\text { pegawai } \\
\text { yang tidak } \\
\text { sesuai } \\
\text { dengan } \\
\text { kemampua } \\
\text { nnya }\end{array}$ \\
\hline
\end{tabular}

Sumber : Sekretariat DLH Kota Sukabumi (2018).

Berdasarkan tabel 1, penempatan pegawai pada Dinas Lingkungan Hidup Kota Sukabumi belum dapat dikatakan optimal, hal ini terlihat dari penempatan pegawai yang tidak sesuai dengan latar belakang pendidikannya atau kemampuannya masih terlalu signifikan yaitu sebesar $46,7 \%$, maka dengan belum optimalnya penempatan pegawai pada DLH Kota Sukabumi tersebut, kinerja yang dihasilkan oleh DLH juga belum optimal

Tabel 2.

Kinerja DLH Tahun 2016 - 2017

\begin{tabular}{|l|c|c|c|c|c|}
\hline \multirow{2}{*}{ Uraian } & $\begin{array}{c}\text { Jumla } \\
\mathrm{h}\end{array}$ & \multicolumn{4}{|c|}{ Penempatan Pegawai } \\
\cline { 3 - 6 } & $\begin{array}{c}\text { Pega } \\
\text { wai }\end{array}$ & $\begin{array}{c}\text { Sesuai } \\
\text { Pendidika } \\
\mathrm{n}\end{array}$ & $\%$ & $\begin{array}{c}\text { Tidak } \\
\text { Sesuai } \\
\text { Pendidikan }\end{array}$ & $\%$ \\
\hline $\begin{array}{l}\text { Penempatan } \\
\text { Pegawai }\end{array}$ & 60 & 32 & $\begin{array}{c}53, \\
3\end{array}$ & 28 & $\begin{array}{c}46, \\
7\end{array}$ \\
\hline
\end{tabular}

Sumber: Sekretariat DLH Kota Sukabumi (2018).

Dari tabel 2 jelas sekali terlihat kemampuan pegawai DLH dalam pengelolaan lingkungan hidup di Kota Sukabumi sangat mempengaruhi terhadap kualitas kinerja entitas tersebut yang cenderung menurun, terlihat pada tahun 2016 dari target $80 \%$ yang terealisasi hanya $75 \%$ dan pada tahun 2017 dari target yang direncanakan sebesar $80 \%$ hanya tercapai $70 \%$.

Berdasarkan uraian diatas, rumusan masalah yang dapat diambil dalam penelitian ini sebagai berikut : 1) Sejauhmana kemampuan pegawai pada Dinas Lingkungan 
Hidup Kota Sukabumi? Sejauhmana kinerja pegawai pada Dinas Lingkungan Hidup Kota Sukabumi? Sejauhmana peranan kemampuan pegawai terhadap kinerja pegawai pada Dinas Lingkungan Hidup Kota Sukabumi?.

Tujuan penelitian ini sendiri adalah : 1) Untuk mengetahui kemampuan pegawai pada Dinas Lingkungan Hidup Kota Sukabumi; 2) Untuk mengetahui kinerja pegawai pada Dinas Lingkungan Hidup Kota Sukabumi, dan 3) Untuk mengetahui efek kemampuan pegawai terhadap kinerja pegawai pada Dinas Lingkungan Hidup Kota Sukabumi.

\section{Metode Penelitian}

\subsection{Rancangan Penelitian}

Rancangan penelitian ini adalah deskriptif asosiatif, melalui survei dengan mengambil sampel dari suatu populasi, dan menggunakan kuesioner sebagai alat pengumpulan data. Metode survei berupaya untuk membedah atau mengkaji secara mendalam mengenai gejala-gejala dari suatu kejadian yang ada. Apabila dilihat berdasarkan tingkat eksplanasi, metode penelitian yang digunakan merupakan gabungan dari metode deskriptif dan metode asosiatif.

\subsection{Populasi dan Sampel}

Populasi dari penelitian ini adalah seluruh pegawai DLH Kota Sukabumi sebanyak 60 orang pegawai. Dengan demikian maka jumlah responden yang diteliti sebanyak jumlah populasi yaitu 60 orang pegawai DLH Kota Sukabumi.

\subsection{Operasional Variabel}

Dalam memudahkan penelitian dan untuk lebih terfokus pada sasaran dan tujuan penelitian, maka variabel yang digunakan dalam penelitian ini adalah variabel bebas (independen) sebagai variabel $\mathrm{X}$ adalah Kemampuan Pegawai dan variabel tidak bebas (dependen) sebagai variabel $Y$ adalah Kinerja Pegawai. Agar penelitian ini berjalan seperti apa yang dikehendaki, maka akan diuraikan mengenai batasan dari variabelvariabel yang ada beserta indikator- indikator untuk mencapai kearah itu.

\subsection{Metode Analisis Data}

Uji instrumen menggunakan uji validitas dan reliabilitas, dengan cara setelah data terkumpul dan benar-benar lengkap kemudian dilakukan uji validitas dan reliabilitas.

Pertanyaan mendasar untuk mengukur reliabilitas data adalah bagaimana konsisten data yang dikumpulkan. Pengujian reliabilitas konsisten internal (internal consistency) dengan menggunakan koefisien Alpha Cronbach.

\subsection{Analisis Efek}

Dalam penelitian ini analisis statistik yang diambil adalah analisis deskriptif. Kajian deskriptif dilakukan untuk mengetahui dan menjelaskan variabel-variabel dari sebuah situasi atau keadaan.

Untuk menghitung besarnya derajat hubungan antara variabel, menggunakan $R$ ho Spearman (rs). Menghitung Rho Spearman, masing-masing variabel harus dirangking terlebih dahulu dari terkecil hingga terbesar.

Untuk melihat derajat keeratan antara variabel independen dan variabel dependen digunakan kriteria Champion.

\section{Hasil dan Pembahasan}

\subsection{Penilaian Kemampuan Pegawai}

Hasil penelitian yang telah dilakukan memperlihatkan penilaian responden terhadap variabel kemampuan pegawai pada DLH Kota Sukabumi. Dengan melihat nilai frekuensi dari jawaban responden terhadap 9 indikator digunakan.

Secara keseluruhan maka dapat diketahui dari 9 indikator kemampuan pegawai terdapat 7 indikator yang dinilai baik oleh responden adalah sebagai berikut:

1. Kemampuan melaksanakan Peraturan (73,3\% responden menyatakan setuju dan $11,7 \%$ menyatakan sangat setuju).

2. Keterampilan bekerja $(66,7 \%$ responden menyatakan setuju, dan $16,7 \%$ menyatakan sangat setuju).

3. Menyelesaikan Masalah (60,0\% responden menyatakan setuju dan $25,0 \%$ menyatakan sangat setuju).

4. Menjalin hubungan $(78,3 \%$ responden menyatakan setuju dan $10,0 \%$ menyatakan sangat setuju).

5. Beradaptasi dengan Lingkungan $(78,3 \%$ responden menyatakan setuju dan 3,3\% menyatakan sangat setuju).

6. Saling Membantu (70,0\% responden menyatakan setuju dan $6,7 \%$ menyatakan sangat setuju).

7. Memiliki Pengetahuan (53,3\% responden menyatakan setuju dan $25,0 \%$ menyatakan sangat setuju).

Sedangkan 2 indikator lagi masih dinyatakan ragu-ragu oleh responden, yaitu:

1. Membuat perencanaan $(56,7 \%$ responden menyatakan ragu-ragu).

Memiliki Gagasan atau Ide

2. ( $46,7 \%$ responden menyatakan ragu-ragu) 


\subsection{Penilaian Kinerja Pegawai}

Secara keseluruhan maka dapat diketahui dari 5 indikator Kinerja pegawai terdapat 3 indikator yang dinilai baik oleh responden, yaitu sebagai berikut:

1. Ketepatan/Keakuratan $\quad(68,3 \%$ responden menyatakan setuju dan $11,7 \%$ menyatakan sangat setuju)

2. Ketelitian $(48,3 \%$ responden menyatakan setuju dan $5,0 \%$ responden menyatakan sangat setuju)

3. Keterampilan $(60,0 \%$ responden menyatakan setuju dan $8,3 \%$ menyatakan sangat setuju)

Sedangkan 2 indikator lagi masih dinyatakan ragu-ragu oleh responden, yaitu:

1. Tercapai target $(55,0 \%$ responden menyatakan ragu-ragu)

2. Kecepatan penyelesaian (58,3\% responden menyatakan ragu-ragu)

\subsection{Efek Kemampuan Pegawai terhadap Kinerja Pegawai}

Tabel 3. Analisis Korelasi

\begin{tabular}{|c|c|c|r|r|}
\hline \multicolumn{5}{|c|}{ Correlations } \\
\hline & & $\begin{array}{c}\text { kemam } \\
\text { puan }\end{array}$ & $\begin{array}{c}\text { kinerj } \\
\mathrm{a}\end{array}$ \\
\hline $\begin{array}{c}\text { Spearma } \\
\text { n's rho }\end{array}$ & $\begin{array}{c}\text { kemam } \\
\text { puan }\end{array}$ & $\begin{array}{c}\text { Correlation } \\
\text { Coefficient }\end{array}$ & 1.000 & $.863^{* *}$ \\
\cline { 3 - 5 } & & Sig. (2-tailed) & .000 \\
\cline { 3 - 5 } & kinerja & $\begin{array}{c}\text { Correlation } \\
\text { Coefficient }\end{array}$ & $.863^{* *}$ & 1.000 \\
\cline { 3 - 5 } & & Sig. (2-tailed) & .000 & 60 \\
\cline { 3 - 5 } & $\mathrm{N}$ & 60 & 60 \\
\hline
\end{tabular}

**. Correlation is significant at the 0.01 level (2tailed).

Sumber : Data primer diolah (2018).

Berdasarkan hasil analisis dengan uji rho spearman's dari table di atas dapat dilihat nilai korelasi (hubungan) kemampuan pegawai dengan kinerja pegawai sebesar $r=0.863$, sehingga dapat dihitung nilai koefisien determinasi sebagai berikut:

$$
\begin{aligned}
\mathrm{Kd} & =\mathrm{r}^{2} \times 100 \% \\
\mathrm{Kd} & =(0.863)^{2} \times 100 \% \\
\mathrm{Kd} & =74,48 \%
\end{aligned}
$$

Nilai koefisien determinasi $(\mathrm{Kd})$ tersebut menunjukan besarnya efek dari kemampuan pegawai terhadap variabel kinerja pegawai yaitu sebesar $74,48 \%$. Artinya bahwa peningkatan kemampuan pegawai akan berperan sebesar $74,48 \%$ terhadap peningkatan kinerja pegawai, sedangkan sisanya sebesar $25,52 \%$ dipengaruhi oleh variabel-variabel lain diluar variabel kemampuan pegawai. Sifat peranannya positif yang artinya peningkatan kemampuan pegawai akan memberikan efek terhadap peningkatan kinerja pegawai.

\section{Kesimpulan}

Berdasarkan hasil dan pembahasan, maka dapat disimpulkan :

a. Dari hasil penilaian variabel kemampuan pegawai yang terdiri dari 9 indikator, dapat disimpulkan bahwa terdapat 7 indikator dari variabel kemampuan pegawai yang dinilai baik oleh responden, yaitu indikator: 1) Kemampuan Melaksanakan peraturan, 2) Keterampilan bekerja, 3) Menyelesaikan masalah, 4) menjalin hubungan, 5) Beradaptasi dengan lingkungan, 6) Saling membantu dan 7) memiliki pengetahuan. Sedangkan 2 indikator dinilai kurang baik atau ragu-ragu, yaitu indikator 1) Membuat perencanaan dan 2) Memiliki gagasan atau ide

b. Dari hasil penilaian terhadap variabel kinerja pegawai yang terdiri dari 5 indikator, maka dapat disimpulkan bahwa terdapat 3 indikator kinerja pegawai di nilai baik oleh responden yaitu: 1) ketepatan/keakuratan, 2) Ketelitian, dan 3) Keterampilan. Sedangkan 2 indikator dinilai kurang baik yaitu rata-rata responden masih menyatakan ragu-ragu terhadap indikator 1) Tercapai target dan 2) Kecepatan penyelesaian.

c. Nilai koefisien determinasi sebesar $74,48 \%$ menunjukkan besarnya efek dari kemampuan pegawai terhadap kinerja pegawai, sisanya sebesar $25,52 \%$ dipengaruhi oleh variabel lain.

\section{Referensi}

Antaranews.com. (2018). Sukabumi hasilkan 165 ton sampah setiap hari. ANTARANEWS.COM. Retrieved from https://www.antaranews.com/berita/689 192/sukabumi-hasilkan-165-tonsampah-setiap-hari. Diunduh pada tanggal 25 November 2018.

Bangun, W. (2012). Manajemen Sumber Daya Manusia. Jakarta: Erlangga.

Basri, A. F. M., \& Rivai, V. (2005). 
JURNAL SWABUMI, Vol. 7 No.1 Maret 2019, pp. 72 76

ISSN: 2355-990X

Performance Appraisal. Jakarta: PT. Raja Grafindo Perkasa.

Hasibuan, M. S. P. (2011). Manajemen Dasar Pengertian dan Masalah (Cetakan 9). Jakarta: Bumi Aksara.

Ilmarinen, J. (2009). Work ability - a comprehensive concept for occupational health research and prevention. Scandinavian Journal of Work, Environment \& Health, 35(1), 1-5. https://doi.org/htp:// dx.doi.org/10.5271/sjweh.1304

Mangkunegara, A. A. P. (2013). Manajemen Sumber Daya Manusia Perusahaan. Bandung: Remaja Rosda Karya.

Perwalkot. Peraturan Walikota Sukabumi No. 35 Tahun 2016 tentang Kedudukan, Susunan Organisasi, Tugas Pokok, Fungsi, dan Tata Kerja Dinas Lingkungan Hidup, Pub. L. No. No. 35 (2016). Kota Sukabumi, Indonesia.

Pojokjabar.com. (2017). Kinerja Dinas Lingkungan Hidup Kota Sukabumi Dipertanyakan. Pojokjabar.Com. Retrieved from https://jabar.pojoksatu.id/sukabumi/2017 /04/19/kinerja-dinas-lingkungan-hidupkota-sukabumi-dipertanyakan/3/.

Diunduh pada tanggal 25 November 2018.

Tabiu, A., Pangil, F., \& Othman, S. Z. (2016). HRM practive and employee performance: mediation of ability, motivation and opportunity. Asian Journal of Multidisciplinary Studies, 4(May, 6), 130-136. Retrieved from http://repo.uum.edu.my/21205/ 